\title{
DO CASTELO PARA A REDE, DA EUROPA PARA A AMÉRICA Aplicação da Teoria da interconstitucionalidade na Corte Interamericana
}

\author{
Clovis Demarchi* \\ Jaine Cristina Suzin ${ }^{* *}$
}

\begin{abstract}
RESUMO
A liberdade adquirida com o avanço tecnológico permite trocas entre indivíduos e organizações que perpassam as fronteiras dos Estados, ignorando o poder-estatal, em um mundo globalizado. Essa complexidade reflete-se no mundo jurídico, pois o direito é um produto cultural, compelindo o surgimento de teorias a explicar novos fenômenos sócio jurídicos de intercâmbio constitucional. O presente artigo visa apresentar a teoria da interconstitucionalidade, surgida no velho mundo, e analisar a sua aplicação na América Latina, por meio das decisões da Corte Interamericana de Direitos Humanos.
\end{abstract}

PALAVRAS CHAVE: Globalização, União Europeia, teoria da interconstitucionalidade, Corte Interamericana dos Direitos do Homem.

\begin{abstract}
The freedom gained from contemporary technological advancement allows for exchanges between individuals and organizations that cross state boundaries while ignoring state power in a globalized world. This current complexity is reflected in the legal world, since the law is a cultural product, compelling the emergence of theories to explain new socio-legal phenomena of constitutional exchange. The purpose of this article is to understand the theory of interconstitutionality and analyze its application in Latin America through the decisions of the Inter-American Court of Human Rights.
\end{abstract}

KEYWORDS: Globalization, European Union, theory of inter-constitutionality, Inter-American Court of Human Rights.

\footnotetext{
* Professor titular da Universidade do Vale do Itajaí nos cursos de graduação, especialização e no Curso de Mestrado em Ciência Jurídica.

** Especialização em Direito Constitucional pela Universidade do Sul de Santa Catarina (2009).
} 


\section{CONSIDERAÇÕES INTRODUTÓRIAS}

Segundo Lipvostzy e Charles (2014, p. 55) a era do pósmoderno coloca em relevo a reorganização profunda do modo de funcionamento sociocultural das sociedades democráticas avançadas, com um liberalismo mundializado, comercialização quase geral dos modos de vida e individualização galopante. Malgrado ainda recente, o pós-moderno já se apresenta obsoleto ante a modernização desenfreada feita de mercantilização proliferante, de desregulações econômicas e furor tecnocientífico, em uma era do "hiper", ou seja, uma modernidade elevada a potência superlativa. Como bem coloca o autor, "o pássaro de Minerva anunciava o nascimento do pós-moderno no momento em que já se esboçava a hipermodernização do mundo".

Disso decorre a transformação da sociedade mundial hodierna, ampliando, em consequência, as relações jurídicas. Tal complexidade tem levado a uma releitura não somente da sociedade, mas também do poder-estatal, porquanto agora o poder é partilhado, ante o surgimento/fortalecimento de forças transnacionais, dentre as quais, a União Europeia, demandando integração e intercâmbio constitucional. (FERNANDES e SANTOS, 2014).

Nesse cenário, o constitucionalismo sofre críticas no sentido de que já não se mostra capaz de enquadrar adequadamente as sociedades plurais e pós-estaduais do nosso tempo. (CANOTILHO, 2008). Surgindo daí diversas teorias com objetivo de discutir o constitucionalismo global (CANOTILHO, 2006, p. 261), dentre as principais, se encontram o constitucionalismo multinível, o transconstitucionalismo e a interconstitucionalidade, sendo essa última teoria o foco do presente estudo.

\section{DO CASTELO PARA A REDE}

De início, é preciso entender o que vem a ser uma teoria da constituição para então compreender a teoria da interconstitucionalidade. Segundo Vaz, à teoria da constituição pertence indagar acerca das possibilidades e limites da força normativa da Constituição. Incumbe-lhe descrever, explicar e seriar os fundamentos ideais e materiais da Constituição e compreender as suas condições histórico-culturais de desenvolvimento e de otimização, 
destacando as complexas relações entre a constituição e a realidade constitucional. Assim, é da teoria da constituição a função de identificar e ordenar as teorias, as tendências e os (pré) juízos que tendem a determinar - consciente ou inconscientemente - os resultados de aplicação do direito constitucional. (VAZ, 2015, p. 15)

Ante o cenário globalizado que se nos apresenta, como processo policêntrico que envolve vários domínios de atividade, tais quais, economia, política, tecnologia, militar, cultural e ambiental, os conceitos jurídicos então existentes já não são mais suficientes a compreender os fenômenos sócio-político-jurídicos em formação, (CANOTILHO, 2006, p. 294-295).

Alcançando tal fenômeno, Lucas Pires (PIRES, 1998) introduz a teoria da interconstitucionalidade em Portugal que, mais tarde, foi desenvolvida por J. J. Gomes Canotilho. Referida teoria tem por escopo compreender o problema da articulação entre os poderes constituintes com fontes e legitimidades diferentes e, por consequência, as relações interconstitucionais de concorrência, convergência e posições de conflito entre as suas constituições, justapondo-as.

Canotilho (2006, p. 283) explica que para compreender os desafios constitucionais da internacionalização, da globalização e da regionalização é necessário passar por rupturas paradigmáticas, tais como: 1) superar o referencial Constituição-Estado; 2) ultrapassar as teorias dos "momentos constitucionais" isoladas e únicas e compreender o "constitucionalismo evolutivo"; e 3) substituir o esquema hierárquico-normativo do direito constitucional por um sistema multipolar de governança constitucional.

E a União Europeia, como fenômeno organizativo em gestação (CANOTILHO, 2006, p. 205), sem se enquadrar em nenhum dos conceitos jurídico-políticos tradicionais que compõem o estado democrático de direito, como se conhece até o presente momento, tem sido agraciada com a alcunha de "objeto político não identificado", nas palavras de Jacques Delors (SILVEIRA, 2017). O que, segundo Pires pode se constituir na primeira fórmula verdadeiramente pós-moderna, contribuindo, sobremaneira, para o surgimento de um novo constitucionalismo. Isso porque, conforme Pires (1998), "os modelos de autoridade hierárquica e de normação piramidal cedem lugar a estruturas e processos de interação, 
coordenação e cooperação". Para Silveira (2015), diferentemente dos Estados federais, cujos processos de decisão são o resultado da combinação de processos decisórios que ocorrem entre os EstadosMembros e as instituições; na União Europeia, o sistema de governação é multinível. Isso porque, segundo a mesma autora, não há uma única liderança na União Europeia, demandando, para suas decisões, "a combinação de procedimentos formais e informais de mediação entre representantes públicos, por um lado, e entre estes e os representantes de interesses privados, por outro". Sendo, pois, por isso que a teoria das redes, ou teoria da interconstitucionalidade, a seguir explicada, bem a representa.

Para Maduro (2006, p. 8), a União Europeia constitui uma comunidade política emergente que comporta reinvindicação de autoridade normativa e política independente, porém não detém poder constituinte como o das comunidades políticas nacionais. Seu constitucionalismo assenta em uma legitimidade plural. Desta forma, observa-se que a teoria da interconstitucionalidade visa promover a interação entre diversas e distintas ordens jurídicas entendendo-se que não haja uma única instância decisória na UE, em relação a conteúdo jurídico-constitucional.

De acordo com Canotilho (2006, p. 268-269) a teoria da interconstitucionalidade possui elementos básicos, quais sejam, a autodescrição e a interorganização das constituições nacionais. Sendo que o primeiro representa um texto autorreferente, conservando a memória e a identidade política que, quando inseridos em uma rede interconstitucional, assumem-se como auto referência. Por essa razão é que o autor usa a metáfora de que estas constituições desceram do "castelo para a rede", sem perderem o seu papel identificador.

A auto referência leva à interculturalidade constitucional que, segundo Canotilho, é a partilha de culturas ou concepções de encarar o mundo e os outros. O mesmo autor conceitua cultura, segundo visão haberliana, como o conjunto de "atitudes, ideias, experiências, padrões de valores, de expectativas, padrões de valores, de expectativas de ações e comportamentos objetivos dos cidadãos e dos grupos plurais.” (HÄBERLE, 1998, p. 20).

Já o segundo elemento, interorganização, é a necessidade auto descritiva da organização superior. Para Canotilho (2006, p. 270) não 
há consenso se a autodescrição interorganizativa pressupõe um texto constitucional auto descritivo ou a descrição pode resultar da assumpção de textos inicialmente concebidos como convenções interestatais. Como exemplo, alguns dos princípios previstos nos Tratados da União Europeia são aludidos como constitucionais pelo Tribunal de Justiça da União Europeia (TJUE), consubstanciados pelo princípio do primado (artigo 4. ${ }^{\circ}$ do TUE).

A primeira manifestação do TJUE acerca do princípio do primado do direito da União foi o caso Costa \& Ennel, em que o pedido de reenvio prejudicial colocou em evidência as relações constitucionais entre a União Europeia e os Estados-Membros. Isso porque, o problema subjacente a todo reenvio prejudicial é o da coexistência de duas normas jurídicas contrárias, mas igualmente aplicáveis na ordem interna dos Estados-Membros; uma proveniente da norma constitucional da União e a outra, da norma constitucional interna, dos Estados-Membros.

Nesse sentido, o papel do TJUE é (e tão somente) identificar qual das normas "conflitantes" é a que melhor se coaduna à hipótese levantada pelo Tribunal nacional quando do reenvio, deixando para esse último a sua aplicação ao caso concreto. Não se trata de declarar a inconstitucionalidade de uma norma em deferência a outra, mas, simplesmente, dar preferência aplicativa, sem qualquer análise acerca da (in) constitucionalidade, ante a inexistência de hierarquia de normas provenientes de distintas fontes, como foi o caso da União Europeia. Esse o processo é o objeto de estudo da teoria da interconstitucionalidade.

No caso Costa \& Ennel, a conclusão do TJUE foi de que a União Europeia (então Comunidade) possui uma ordem jurídica própria, integrada pelos sistemas jurídicos dos seus Estados-Membros. E que, ao assinarem os Tratados instituidores, os Estados-Membros transferiram direitos e obrigações da ordem jurídica interna para a ordem jurídica da União, implicando em uma limitação definitiva dos seus direitos soberanos, criando, assim, um conjunto de normas aplicável aos seus nacionais e a si próprios que não pode ser ignorado e muito menos preterido pelo direito interno (UNIÃO EUROPEIA, 1964). A obrigatoriedade de tal observância por parte dos EstadosMembros e também da própria União Europeia decorre do princípio da lealdade europeia e de seus corolários, em especial o do primado. 
Percebe-se a importância do caso Costa \& Ennel teve sobre o direito da União ao ler as declarações anexadas à ata final da Conferência Intergovernamental que adotou o Tratado de Lisboa, que assim dispõe:

17. Declaração sobre o primado do direito comunitário. A Conferência lembra que, em conformidade com a jurisprudência constante do Tribunal de Justiça da União Europeia, os Tratados e o direito adotado pela União com base nos Tratados primam sobre o direito dos Estados-Membros, nas condições estabelecidas pela referida jurisprudência. Além disso, a Conferência decidiu anexar à presente Ata Final o parecer do Serviço Jurídico do Conselho sobre o primado do direito comunitário constante do documento 11197/07 (JUR 260): "Parecer do Serviço Jurídico do Conselho de 22 de junho de 2007. Decorre da jurisprudência do Tribunal de Justiça que o primado do direito comunitário é um princípio fundamental desse mesmo direito. Segundo o Tribunal, este princípio é inerente à natureza específica da Comunidade Europeia. Quando foi proferido o primeiro acórdão desta jurisprudência constante (acórdão de 15 de julho de 1964 no processo 6/64, Costa contra ENEL (1)), o Tratado não fazia referência ao primado. Assim continua a ser atualmente. $\mathrm{O}$ facto de o princípio do primado não ser inscrito no futuro Tratado em nada prejudica a existência do princípio nem a atual jurisprudência do Tribunal de Justiça. (UNIÃO EUROPEIA, 2012, p. 346).

Observa-se que a União Europeia se apresenta como uma comunidade política que garante uma autoridade normativa e política independente e o seu paradigma hermenêutico do direito é de direito constitucional e não de direito internacional.

No mesmo sentido, leciona Silveira (2011, p. 28), que o paradigma de construção da União Europeia é constitucional e não internacionalista, porquanto a União Europeia se comporta e evolui como se sua base jurídica (tratados constitutivos) fosse uma constituição. Da mesma forma que o estado de direito possui instituições próprias, processos de interpretação de normas e mecanismos sancionatórios de sua eventual violação; a União Europeia também os tem, respondendo sob a alcunha de "União de direitos", tal qual o Estado é conhecido como "Estado de direito", em clara alusão aos direitos fundamentais reconhecidos nos Tratados instituidores aos cidadãos da União. 
Portanto, a teoria em estudo serve para acomodar/emparelhar as reivindicações de autoridades constitucionais que convivem em um mesmo espaço jurídico-constitucional não hierarquicamente estruturado, como se apresenta a União Europeia. Essa necessidade de acomodação surge com o diálogo entre o TJUE e os tribunais nacionais, compelido pelos cidadãos na busca pela garantia de direitos oriundos da cidadania da União.

Porém, conforme Canotilho (2006, p. 266), o fenômeno não é privilegio da União Europeia, porquanto, a idade medieval já nos apresentava diversas ordens jurídicas convivendo no mesmo espaço político. Assim como, os novos arranjos jurídicos da sociedade moderna estão nos mostrando a viabilidade da aplicação da teoria da interconstitucionalidade para além da Europa, tal como a sua aplicação na América Latina, por meio da Corte Interamericana dos Direitos Humanos. (RIBEIRO e ROMANCINI, 2015).

\section{A TEORIA DA INTERCONSTITUCIONALIDADE E A CORTE INTERAMERICANA DE DIREITOS HUMANOS}

\subsection{A Corte}

A Corte Interamericana de Direitos Humanos (Corte) é um organismo judicial do Sistema Interamericano de Proteção dos Direitos Humanos, cuja sede é em São José, na Costa Rica, oficialmente instalada em 22 de novembro de 1969, juntamente com a Comissão Interamericana. $\mathrm{O}$ sistema interamericano, juntamente com os sistemas europeu e africano, compõe a tríade que assegura a eficácia dos direitos e liberdades garantidos internacionalmente, compelindo a impunidade de suas violações por parte dos EstadosMembros. (AMARAL JÚNIOR, 2013, p. 530-531).

O seu papel principal é de guardiã da Convenção Americana de Direitos Humanos (Convenção Americana), sendo competente em diversas matérias de direitos humanos, como o direito à vida; o direito à integridade pessoal; o direito de proteção judicial; o direito de garantias processuais e o direito de igualdade de proteção da lei. A corte é composta por sete juízes, dentre juristas da mais alta autoridade moral e de reconhecida competência em matéria de direitos humanos, por votação secreta, por maioria absoluta dos 
Estados-Membros da Convenção Americana, por um período de seis anos, com possibilidade de reeleição, vedada a existência de dois juízes de mesma nacionalidade. O quórum para julgamento é de cinco juízes e a Comissão, necessariamente, participa de todos (SALDANHA e VIEIRA, 2015, p. 67).

Dentre suas competências, estão a consultiva e a contenciosa. No plano consultivo, a Corte recebe consultas dos Estados-Membros da Organização dos Estados Americanos (OEA) e dos signatários do Pacto de São José acerca da interpretação e alcance da Convenção Americana ou de outros tratados concernentes à proteção dos direitos humanos nos Estados americanos. Segundo artigo 64 da Convenção, "a Corte, a pedido de um Estado membro da Organização, poderá emitir pareceres sobre a compatibilidade entre qualquer de suas leis internas e os mencionados instrumentos internacionais." (OEA, CIDH, 1969).

Na competência contenciosa, a Corte julga casos de violação de direitos previstos na norma internacional por parte dos EstadosMembros da Convenção Americana. Suas decisões são vinculantes aos Estados-Membros que aderirem à Convenção. Há possibilidade de, no momento do depósito, haver declaração incondicional ou com condição de reciprocidade, por prazo determinado ou para casos específicos. A título de exemplo, o Brasil aderiu à Convenção em 1992, com aceitação da Corte em 1998, sem aceite do direito automático de visitas e investigações in loco da Comissão. (OEA, CIDH, 1969).

Segundo dispõe o artigo $61^{\circ}$ da Convenção Americana (OEA, CIDH, 1969), somente os Estados partes e a Comissão têm direito a submeter casos à apreciação da Corte, desde que esgotados o procedimento previsto nos artigos $48^{\circ}$ a $50^{\circ}$ da mesma Convenção. Em resumo, tais dispositivos preveem processo anterior, sob a competência da Comissão, em um juízo de admissibilidade e de tentativa de composição amigável.

\subsection{A aplicação da teoria da interconstitucionalidade pela Corte}

Ao contrário do que se apresenta na União Europeia, tratandose de uma organização internacional sui generis, cujo direito da União possui primazia sobre o dos Estados-Membros, na América 
Latina, a OEA se apresenta como uma organização internacional tradicional. Portanto, na América Latina, somente os EstadosMembros da OEA e que ratificaram a Convenção estão a ela submetidos, assim como à jurisdição da Corte e da Comissão, ressalvadas as possíveis restrições de tempo e de matéria, conforme já esclarecido alhures.

Dito isso, para analisar a ocorrência da interconstitucionalidade na América Latina, necessário revisitar os parâmetros criados por Canotilho (2006, p. 266), quais sejam, concorrência, convergência e justaposição, pois a teoria da interconstitucionalidade surge para compreender as "relações interconstitucionais de concorrência, convergência, justaposição e conflitos de várias constituições e de vários poderes constituintes no mesmo espaço político."

Com base nesses critérios, passa-se à análise do parecer consultivo OC-18, de 17 de setembro de 2003, ante seu caráter paradigmático frente aos direitos humanos, pois foi a primeira vez que a Corte afirmou que o jus cogens não tem limitação aos direitos dos tratados. Segundo voto do juiz Antônio Augusto Cançado Trindade, que acompanha o parecer, a opinião consultiva deu importante passo rumo à humanização do direito internacional, pois o despertar da consciência jurídica universal, fonte material de todo direito, é necessário para proteger os direitos inerentes a todo ser humano em toda e qualquer situação.

A preocupação do governo mexicano que seu ensejo à consulta em questão foi, em resumo, a privação do desfrute e exercício de determinados direitos trabalhistas de migrantes indocumentados (por exemplo: pagamento de horas extras, antiguidade no emprego, salários atrasados, licença maternidade). $\mathrm{O}$ Estado levantou a questão da observância, por partes dos EstadosMembros, de princípios tais como, o da igualdade jurídica, não discriminação e proteção igualitária e efetiva da lei, consagrados em instrumentos internacionais de proteção aos direitos humanos.

As normas indicadas expressamente no pedido foram as seguintes: Carta da Organização dos Estados Americanos (artigos 3.1 e 17); Declaração Americana (artigo II, que trata do direito de igualdade perante a lei; artigo 1.1, que trata da obrigação de respeitar os direitos; artigo 2, que trata do dever de adotar disposições de direito interno e o 
artigo 24, que trata da igualdade perante a lei); Declaração Universal dos Direitos Humanos (artigos 1, 2.1 e 7); e Pacto Internacional sobre Direitos Civis e Políticos (artigos 2.1, 2.2, 5.2 e 26).

Logo de início, a Corte reafirmou que possui competência consultiva, nos termos do artigo 64.1 da Convenção Americana, para se manifestar acerca de interpretação de regras internacionais. Argumentou, ainda, que possui competência quando a questão trata de direitos humanos, mesmo que o tratado invocado não provenha do mesmo sistema regional de proteção, tal como os instrumentos invocados na consulta, pois "todos protegem direitos humanos e são aplicáveis aos Estados americanos" (OEA, CIDH, 2003, p. 89-90, item 53-55). Tal afirmação já é assenta na Corte desde o primeiro parecer consultivo, em 1982.

Segundo entendimento da Corte, um parecer consultivo pode "conduzir a alterar ou a debilitar, em detrimento do ser humano, o regime previsto pela Convenção. " (OEA, CIDH, 2003, p. 91), ou seja, não há limites quando o assunto em debate é a proteção dos direitos humanos. Tanto assim, que no Parecer Consultivo $\mathrm{n}^{\mathbf{0}} 16$ (OEA, CIDH, 1999) a Corte já havia sedimentado a possibilidade ser objeto de consulta uma norma que diga com os direitos humanos, nada obstante não ser o seu tema central, tal como a Convenção de Viena sobre relações consulares, objeto daquele parecer. (SALDANHA E VIEIRA, 2015, p. 67)

Assim, a Corte deixa claro o caráter fundamental dos direitos humanos, pois toda a pessoa tem atributos invioláveis e inerentes à dignidade humana e, por isso, "são superiores ao Estado, independentemente de sua organização política". Ainda, afirmou a Corte que a violação dos direitos humanos, por ação ou omissão por parte de um Estado parte da Convenção Americana gera responsabilidade internacional, independentemente de qual autoridade a tenha cometido/omitido e/ou de ter extrapolado os limites de sua competência. (OEA, CIDH, 2003, p. 91/97. Item 61/73)

Até porque, segundo o princípio do effet utile, o Estado parte deve envidar todos os esforços para o previsto na Convenção Americana seja efetivamente cumprido em seu ordenamento jurídico interno. Trata-se de uma regra consuetudinária que prescreve que o Estado que ratifica um tratado de direitos humanos deve modificar seu direito interno para assegurar o fiel cumprimento das obrigações 
assumidas. Contudo, a Corte deixa claro que não bastam normas internas, necessário se faz medidas positivas a evitar a violação dos direitos humanos. (OEA, CIDH, 2003, p. 99, item 81).

Nesse sentido, os princípios da igualdade perante à lei, da igual proteção da lei em favor de todas as pessoas e da não discriminação estão intrinsicamente ligados à proteção dos direitos humanos, não por menos que estão previstos em uma série de instrumentos internacionais, como dever universal, tais como aqueles indicados pela Corte no Parecer consultivo $\mathrm{n}^{\circ}$ 18, a saber: "Carta da OEA (artigo 3.1); Convenção Americana sobre Direitos Humanos (artigos 1 e 24); Declaração Americana dos Direitos e Deveres do Homem (artigo 2); Protocolo Adicional à Convenção Americana sobre Direitos Humanos em Matéria de Direitos Econômicos, Sociais e Culturais, "Protocolo de San Salvador" (artigo 3); Carta das Nações Unidas (artigo 1.3); Declaração Universal dos Direitos Humanos (artigos 2 e 7); Pacto Internacional sobre Direitos Econômicos, Sociais e Culturais (artigos 2.2 e 3); Pacto Internacional sobre Direitos Civis e Políticos (artigos 2 e 26); Convenção Internacional sobre a Eliminação de Todas as Formas de Discriminação Racial (artigo 2); Convenção sobre os Direitos da Criança (artigo 2); Declaração dos Direitos da Criança (Princípio 1); Convenção Internacional sobre a Proteção dos Direitos de Todos os Trabalhadores Migrantes e dos Membros das suas Famílias (artigos 1, 7, 18.1, 25, 27, 28, 43, 45.1, 48, 55 e 70); Convenção sobre a Eliminação de Todas as Formas de Discriminação contra a Mulher (artigos 2, 3, 5 a 16); Declaração sobre a Eliminação de Todas as Formas de Intolerância e Discriminação Fundadas na Religião ou nas Convicções (artigos 2 e 4); Declaração da Organização Internacional do Trabalho (OIT) relativa aos Princípios e Direitos Fundamentais no Trabalho e ao seu Acompanhamento (2.d); Convenção no 97 da Organização Internacional do Trabalho (OIT) sobre os Trabalhadores Migrantes (revisado) (artigo 6); Convenção n ${ }^{\circ} 111$ da Organização Internacional do Trabalho (OIT) sobre a Discriminação em Matéria de Emprego e Profissão (artigos 1 a 3); Convenção $n^{\circ} 143$ da Organização Internacional do Trabalho (OIT) sobre os Trabalhadores Migrantes (disposições complementarias) (artigos 8 e 10); Convenção $n^{\circ} 168$ da Organização Internacional do Trabalho (OIT) relativa ao Fomento do Emprego e Proteção contra o Desemprego 
(artigo 6); Proclamação de Teerã, Conferência Internacional de Direitos Humanos de Teerã, 13 de maio de 1968 (pars. 1, 2, 5, 8 e 11); Declaração e Programa de Ação de Viena, Conferência Mundial sobre Direitos Humanos, 14 a 25 de junho de 1993 (I.15; I.19; I.27; I.30; II.B.1, artigos 19 a 24; II.B.2, artigos 25 a 27); Declaração sobre os Direitos das Pessoas Pertencentes a Minorias Nacionais ou Étnicas, Religiosas e Linguísticas (artigos 2, 3, 4.1 e 5); Conferência Mundial contra o Racismo, Discriminação Racial, Xenofobia e Intolerância Conexa, Programa de Ação, (parágrafos da Declaração: 1, 2, 7, 9, 10, 16, 25, 38, 47, 48, 51, 66 e 104); Convenção Relativa à Luta contra a Discriminação no Campo do Ensino (artigo 3); Declaração sobre a Raça e os Preconceitos Raciais (artigos 1, 2, 3, 4, 5, 6, 7, 8 e 9); Declaração dos Direitos Humanos dos Indivíduos que não são Nacionais do País onde Vivem (artigo 5.1.b e 5.1.c); Carta dos Direitos Fundamentais da União Europeia (artigos 20 e 21); Convenção Europeia para a Proteção dos Direitos Humanos e das Liberdades Fundamentais (artigos 1 e 14); Carta Social Europeia (artigo 19.4, 19.5 e 19.7); Protocolo $\mathrm{N}^{\circ} 12$ à Convenção Europeia para a Proteção dos Direitos Humanos e das Liberdades Fundamentais (artigo 1); Carta Africana dos Direitos Humanos e dos Povos "Carta de Banjul" (artigos 2 e 3); Carta Árabe dos Direitos Humanos (artigo 2); e Declaração do Cairo sobre os Direitos Humanos no Islã (artigo 1)." (OEA, CIDH, 2003, p. 99, item 86). Acrescenta-se, ainda, o Tratado da União Europeia (artigo 18).

Tais instrumentos de proteção aos direitos humanos são internalizados nos Estados parte por meio de previsão inserta nas suas Constituições. Para exemplificar, a Constituição da República Federativa do Brasil de 1988 (BRASIL, 2017) prevê o status de emenda constitucional a todo e qualquer tratado sobre direitos humanos assinado pelo Estado brasileiro, conforme seu artigo $5^{\circ}, \S 3^{\circ}$. Assim como a Constituição da Argentina, que em seu artigo $75,22^{\circ}$, prevê que os tratados acerca de direitos humanos gozam de hierarquia constitucional. Já a Constituição da Bolívia, em seu artigo $256^{\circ}$ prevê que o nível mais elevado de proteção aos direitos humanos, ao expressar a prevalência de tratados assinados quando sejam mais favoráveis do que os garantidos na Constituição.

Ensina Trindade (2006, p. 111/390) que os direitos humanos são universais, pois já não se sustenta o monopólio estatal da 
titularidade de direitos, muito menos os excessos de um positivismo jurídico degenerado, de um modelo westfaliano do ordenamento internacional esgotado e superado, que excluíram o ser humano do ordenamento jurídico internacional, esquecendo-se que é ele o destinatário final das normas jurídicas. Para o autor, há que se criar uma consciência jurídica universal para reconstruir o direito internacional baseado em um novo paradigma, qual seja, a pessoa humana na posição central e tendo presentes os problemas que afetam a humanidade como um todo.

Esse pensamento está intrinsicamente presente no parecer ora analisado quando a Corte indica que os princípios de igualdade perante a lei, igual proteção da lei a todas as pessoas e não discriminação fazem parte do jus cogens, já que sobre ele descansa todo o arcabouço jurídico da ordem pública nacional e internacional e é um princípio fundamental que permeia todo ordenamento jurídico. Tais princípios devem, portanto, ser obedecidos por todos os Estados, independentemente de fazerem parte de um ou outro tratado internacional, tanto no âmbito internacional, quanto no seu ordenamento interno, segundo uma obrigação de caráter erga omnes. (OEA, CIDH, 2003, p. 103-104, item 100-101)

Ainda, é por esse caráter erga omnes que recai sobre os Estados a obrigação de observância de tais princípios em benefício dos seres humanos sob suas respectivas jurisdições, independentemente do seus status migratórios, devendo os Estados se absterem de tomar medidas que violem tais direitos, assim como, possuem a obrigação de adotar medidas positivas para inibir/coibir situações discriminatórias (princípio do effet utile). (OEA, CIDH, 2003, p. 104-105, item 103/105/109)

Porém, segundo a Corte, "nem toda distinção de tratamento pode ser considerada ofensiva, por si mesma, à dignidade humana", ante a diferenciação entre distinção e discriminação, afirmando que a distinção é possível e aceitável, desde que seja razoável, proporcional e objetiva. Para elucidar, aponta as restrições a determinados direitos políticos em relação à nacionalidade. (OEA, CIDH, 2003, p. 100, item 89).

Já a discriminação, segundo definição formulada pelo Comitê de Direitos Humanos das Nações Unidas é toda "exclusão, restrição ou preferência que se baseie em determinados motivos, como raça, 
cor, sexo, idioma, religião, opinião política ou de outra natureza, origem nacional ou social, posição econômica, nascimento ou qualquer outra condição social, e que tenham por objetivo ou por resultado anular ou prejudicar o reconhecimento, desfrute ou exercício, em condições de igualdade, dos direitos humanos e liberdades fundamentais de todas as pessoas." (OEA, CIDH, 2003, p. 112, item 144).

Assim, a Corte não considera discriminação uma distinção legítima, originária de fato substancialmente diferente, desde que demonstrada a conexão fundamentada entre as diferenças e os objetivos da regra em questão, sendo que esses objetivos não podem estar dissociados da justiça ou da razão. Em outras palavras, "não podem perseguir fins arbitrários, caprichosos, despóticos ou que de alguma maneira conflitante com a essencial unidade e dignidade da natureza humana”. (OEA, CIDH, 2003, p. 101, item 91).

Para a Corte, admite-se distinções objetivas e razoáveis, desde que seja a regra que melhor proteja a pessoa humana, em uma clara alusão ao princípio pro homine (na América Latina) ou "nível mais elevado de proteção" (União Europeia).

O princípio pro homine está expresso no artigo 29 da Convenção Americana, dentre outros, e se assenta na premissa que os instrumentos internacionais de direitos humanos estabelecem que nenhuma de suas disposições autoriza a limitar os direitos protegidos em maior medida que as previstas. Além do que, a limitação ao gozo e exercício de qualquer outro direito é vedada quando podem eles ser reconhecidos em outra norma internacional, ou interna, em vigor. Em suma, está sempre em favor do ser humano. (PINTO, 2004, p.163-171).

Já o nível mais elevado de proteção está previsto expressamente no artigo 53. ${ }^{\circ}$ da Carta de Direitos Fundamentais da União Europeia (CDFUE), como a proibição em restringir ou lesar direitos do homem e liberdades fundamentais reconhecidos pelo direito da União, o direito internacional e as Convenções internacionais em que são Partes a União ou todos os EstadosMembros. (SILVEIRA, 2016, p. 376).

Vê-se, pois, que tais regras de proteção de direitos, servem para sempre avaliar do ponto de vista dos cidadãos em relação à autoridade pública, aquele que se revelar mais favorável ao 
indivíduo, alargando a sua esfera de autonomia face ao Estado, ou conferindo-lhe mais garantias em determinadas situações. (CANOTILHO, 2008, p. 208).

No caso dos migrantes indocumentados, a Corte chegou à conclusão de que a situação regular de uma pessoa em um Estado não é condição necessária para que este Estado respeite e garanta o princípio da igualdade e não discriminação, visto que, como já se mencionou, esses princípios têm caráter fundamental e todos os Estados devem garanti-los a seus cidadãos e a toda pessoa estrangeira que se encontre em seu território. Isso não significa proibição de tratamento distinto aos migrantes documentados ou mesmo aos nacionais - até porque é faculdade do Estado e dos particulares oferecer trabalho aos imigrantes indocumentados. Porém, uma vez mantida relação de trabalho e/ou aceita sua entrada no território do Estado, os direitos humanos devem ser respeitados, sem discriminação alguma por sua permanência regular ou irregular, nacionalidade, raça, gênero ou qualquer outra causa, tal como o direito ao devido processo legal no âmbito civil, trabalhista, fiscal ou de qualquer outra natureza e não apenas penal. (OEA, CIDH, 2003, p. 107-109, item 118-124).

$\mathrm{E}$, por fim, a corte reafirmou a aplicação da norma que mais favoreça a pessoa humana, no caso específico, o trabalhador (nível mais elevado de proteção), ao reconhecer a existência de inúmeros instrumentos jurídicos que regulamentam os direitos trabalhistas, em nível interno e internacional, afirmando que: "se uma prática interna ou uma regra interna favorece mais ao trabalhador do que uma regra internacional, deve ser aplicado o direito interno. Do contrário, se um instrumento internacional beneficia o trabalhador concedendo direitos que não estão garantidos ou reconhecidos internamente, estes deverão ser respeitados e garantidos igualmente. "(OEA, CIDH, 2003, p. 114, item 156).

Essa é a mesma conclusão a que chegou o TJUE, no caso Melloni, ao interpretar que o artigo 53. ${ }^{\circ}$ da CDFUE autoriza um Estado-Membro a aplicar o padrão de proteção de direitos fundamentais previstos na sua Constituição, desde que ele seja mais elevado do que o previsto na CDFHE e bem assim, a afastá-lo, em caso contrário, privilegiando a aplicação do direito da União, por consequência. 


\section{CONCLUSÃO}

Acredita-se que a maior contribuição que a harmonização de ordenamentos jurídicos de diversos Estados tem a oferecer é uma proteção ao ser humano, ao nível máximo. Pois, ao se centralizar os direitos humanos como agregador de diversas normas constitucionais, representantes de diversas culturas, a maior contribuição é a garantia de que o ser humano será protegido com a melhor e a mais garantista das normas em rede, independentemente de sua nacionalidade ou da bandeira da norma aplicada, fazendo com o direito internacional seja, também, constitucional e vice e versa.

Isso resulta do mundo globalizado, pois se é verdade que o poder ultrapassa as fronteiras, ignorando delimitações de poder e de competências, também é verdade que ele serve para a criação de redes de proteção aos direitos do ser humano, para além das fronteiras dos Estados, invadindo os muros dos castelos, outrora intransponíveis, colocando o ser humano no centro das atenções mundiais, para que, quem sabe, as atrocidades provocadas contra incontáveis seres humanos, fique apenas nas tristes lembranças da história mundial.

Neste contexto a teoria da interconstitucionalidade se mostra útil não apenas dentro das muralhas do velho mundo, mas também do outro lado do atlântico - e quiçá donde mais -, onde, ressalvadas as diferenças quanto à questão de tratados e objetivos daí advindos, possui a Corte Interamericana de Direitos do Homem, que se serve de tal teoria para atingir seu objetivo maior, qual seja, dar ao ser humano o nível mais elevado de proteção aos seus direitos, justapondo para isso, um arcabouço de normas oriundas de variados poderes constituintes com fontes e legitimidades diversas.

Desta forma, as constituições dos Estados passam por adaptações para se inserirem no contexto da rede interconstitucional, obrigando-se no âmbito internacional, porém sem deixarem de expressar a identidade cultural e política, em um complexo processo de concorrência e conflitos de diferentes normas constitucionais, mas que possuem o mesmo objeto garantidor e, por esse motivo, acabam convergindo e se justapondo. 


\section{REFERÊNCIAS BIBLIOGRÁFICAS}

ABREU, Joana Covelo de. Cooperação judiciária em matéria civil na União Europeia e cobrança de créditos. Importância da tramitação prejudicial urgente. Revista de la Secretaría del Tribunal Permanente de Revisión. Asunción, Paraguai, a. 5, n. 10, out. 2017.

AMARAL JUNIOR, Alberto. Curso de Direito Internacional Público. São Paulo: Atlas, 2013.

ARGENTINA. Constitucion de la Nacion Argentina (1994). Disponível em: http://www.constitution.org/cons/argentin.html. Acesso em: 23 mar. 2018.

BOLÍVIA. Constitución Política del Estado (2009). Disponível em: https://www.oas.org/dil/esp/Constitucion_Bolivia.pdf. Acesso em: 23 mar. 2018.

BRASIL. Constituição da República Federativa do Brasil de 1988. Brasília: Senado Federal, 2017.

CANOTILHO, José Joaquim Gomes. Brancosos e Interconstitucionalidade: Itinerários dos Discursos sobre a Historicidade Constitucional. Coimbra: Almedina, 2006.

CANOTILHO, Mariana. O Princípio do Nível Mais Elevado de Proteção em Matéria de Direitos Fundamentais (Dissertação de Mestrado), Universidade de Coimbra: Coimbra, 2008.

CORDEIRO, Laís V. O sistema interamericano de proteção dos direitos humanos a partir do constitucionalismo multinível, do transconstitucionalismo e da interconstitucionalidade: desafios e limites. Dissertação (Mestrado em Direitos Humanos). Universidade Federal de Goiás, Goiânia, 2015. Disponível em: https://slidex.tips/download/prazo-suscita-justificativa-junto-a-coordenaaodo-curso-os-dados-do-documento-na. Acesso em: 20 mar. 2018.

FERNANDES, Rodrigo; SANTOS, Rafael Padilha dos. Transnacionalidade e os Novos Rumos do Estado e do Direito. In: Revista Eletrônica Direito e Política, Itajaí, Univali, v. 9, n. 2, 2014.

FROUFE, Pedro Madeira; GOMES, José Caramelo. Mercado Interno e Concorrência. In: SILVEIRA, Alessandra; CANOTILHO, Mariana; FROUFE, Pedro Madeira (Orgs.). Direito da União Europeia: Elementos de Direito e Política da União. Coimbra: Almedina, 2016.

HABERLE, Peter. Verfassungslehre als Kulturwissenschaft. Berlim: Duncker \& Humblot, 1998. 
LIPOVETSKY, Gilles; CHARLES, Sébastiem. Os Tempos Hipermodernos. Lisboa: Edições 70, 2014.

MADURO, Miguel Poiares. Constituição Plural: Constitucionalismo e União Europeia. Cascais: Principia, 2006.

NEVES, Marcelo. (Não) Solucionando Problemas Constitucionais: Transconstitucionalismo além de Colisões. Lua Nova: Revista de Cultura e Política, São Paulo, n. 93, p. 201-232, 2014.

OEA, CIDH. (1969). Convenção americana sobre direitos humanos "pacto de San José de Costa Rica". Disponível em: http://www.dhnet.org.br/direitos/sip/oea/oeasjose.htm. Acesso 18 dez. 2017. OEA, CIDH. (1999). O direito à informação sobre a assistência consular no marco das garantias do devido processo legal. Parecer consultivo OC16/99, 01 de outubro de 1999, solicitado pelos Estados Unidos Mexicanos. Disponível em: http://www.cnj.jus.br/files/conteudo/arquivo/2016/04/9a756 860684845bbcdb9be2389370b73.pdf. Acesso 18 dez. 2017.

OEA, CIDH. (2003). A condição jurídica e os direitos dos migrantes indocumentados. Parecer consultivo OC-18/03, 17 de setembro de 2003, solicitado pelos Estados Unidos Mexicanos. Disponível em: http://www.cnj.jus.br/files/conteudo/arquivo/2016/04/58a49408579728bd7f 7a6bf3f1f80051.pdf. Acesso 18 dez. 2017.

OEA. (1948). Declaração americana dos direitos e deveres do homem. Aprovada na Nona Conferência Internacional Americana, Bogotá, 1948. Disponível em: https://www.cidh.oas.org/basicos/portugues/b.declaracao_amer icana.htm. Acesso $18 \mathrm{dez} .2017$.

OEA. (1967). Carta da organização dos estados americanos. Disponível em: https://www.oas.org/dil/port/tratados_A-

41_Carta_da_Organização_dos_Estados_Americanos.pdf.

Acesso 18 dez. 2017.

ONU. (1966). Pacto Internacional sobre os Direitos Civis e Políticos. Adotado e aberto à assinatura, ratificação e adesão pela resolução 2200-A (XXI) da Assembleia Geral das Nações Unidas, de 16 de dezembro de 1966. Disponível em: http://www.cne.pt/sites/default/files/dl/2_pac_direitos _civis_politicos.pdf. Acesso em: 18 dez. 2017.

ONU. (1948). Declaração universal dos direitos humanos. Adotada e proclamada pela resolução 217 A (III) da Assembleia Geral das Nações Unidas em 10 de dezembro de 1948. Disponível em: http://unesdoc.unesco.org/images/0013/001394/139423por.pdf. Acesso 18 dez. 2017. 
PINTO, Monica. El Principio pro Homine. Criterios de Hermenêutica y Pautas para la Regulacíon de los Derechos Humanos. In: COURTIS, Christian; ABREGÚ, Martín (orgs.) La Aplicación de los Tratados sobre Derechos Humanos por los Tribunales Locales. Buenos Aires: Editores del Puerto, 2004.

PIRES, Lucas. Introdução do Direito Constitucional Europeu: seu Sentido, Problemas e Limites Coimbra: Almedina 1998.

REZEK, Francisco. Direito Internacional Público: Curso Elementar. São Paulo: Saraiva, 2014.

RIBEIRO, Daniela Mengoti; ROMANCINI, Malu. A Teoria da Interconstitucionalidade: uma análise com base na América Latina. In: Revista de Direito Internacional, Brasília: Uniceub, v. 12, n. 2, 2015.

SALDANHA, Jânia Maria Lopes; VIEIRA, Lucas Pacheco. Diálogos Transjurisdicionales. Cidad de México: Editorial Porruá, 2015.

SILVEIRA, Alessandra. Cidadania de Direitos e Comunidade Política Europeia (sobre a Cidadania Europeia que se move dos Tribunais para a Arena Política). In: , DAVID, Sofia (org.) Contencioso da Nacionalidade. 2 ed. Lisboa: Centro de Estudos Judiciários, 2017.

SILVEIRA, Alessandra. Interconstitucionalidade: Normas Constitucionais em Rede e Integração Europeia na Sociedade Mundial. In: WALMOTT, Alexandre; COELHO, Saulo Pinto. Interconstitucionalidade e Interdisciplinaridade: Desafios, Âmbitos e Níveis de Interação no Mundo Global. Uberlândia: Laboratório Americano de Estudos Constitucionais Comparado, 2015.

SILVEIRA, Alessandra. Princípios de Direito da União Europeia. Lisboa: Quid Juris, 2011.

SILVEIRA, Alessandra. Tratado de Lisboa: Versão consolidada. Lisboa: Quid Juris, 2016.

TRINDADE, Antônio Augusto Cançado. A Humanização do Direito Internacional. Belo Horizonte: Del Rey, 2006.

UNIÃO EUROPEIA, (2013). Acórdão do Tribunal de Justiça (Grande Secção) de 26 de fevereiro de 2013. Stefano Melloni contra Ministerio Fiscal. Disponível em: https://eur-lex.europa.eu/legalcontent/EN/TXT/?uri=CELEX:62011CJ0399 .Acesso 18 jan. 2018.

UNIÃO EUROPEIA. Jornal Oficial da União Europeia de 15 de julho de 1964. Disponível em: https://eur-lex.europa.eu/legalcontent/EN/TXT/?uri=CELEX:61964CJ0006. Acesso em: 20 fev. 2018. 
UNIÃO EUROPEIA. Jornal Oficial da União Europeia de 26 de outubro de 2012. Disponível em: http://eurlex.europa.eu/resource.html?uri=cellar:2bf140bf-a3f8-4ab2-b506fd71826e6da6.0022.02/DOC_5format=PDF. Acesso em: 20 fev. 2018.

VAZ, Manuel Afonso. A Teoria da Constituição. O que é a Constituição, hoje? Porto: Editora Porto, 2015. 